\title{
Relationship between left atrial dimensions and global and regional fat depots
}

\author{
Relación entre las dimensiones de la aurícula izquierda y los depósitos globales y \\ regionales de grasa corporal
}

\author{
Macarena C. De Zan*, Patricia M. Carrascosa, Exequiel Reynoso, Alejandro Deviggiano, Héctor Deschle \\ and Gastón A. Rodríguez-Granillo \\ Department of Cardiovascular Imaging, Diagnóstico Maipú. Buenos Aires, Argentina
}

\begin{abstract}
Background and Objectives: The relationship between body fat depots and the left atrial (LA) dimensions has not been fully explored. Our objective is to determine if there is a relationship not only with total body fat depots, but specifically with regional fatty depots. Materials and Methods: It was an observational, retrospective study that included consecutive patients referred to our institution with an order to perform computed tomography angiography triggered by electrocardiogram for different clinical indications. Measurements of the $L A$ were made in the systolic phase, using four and two cameras views. Results: $A$ total of 87 patients were included. The mean age was $66.4 \pm 12.5$ years; $67 \%$ were men. The $L A$ volume indexed by the body surface area was $48.0 \pm 16.6 \mathrm{~cm}^{3} / \mathrm{m}^{2}$. We identified significant correlations between the $L A$ dimensions and the age $(p<0.05)$. However, no significant correlations were found between the LA dimensions and the body fat depots, either total or regional. Conclusions: In this study, we did not identify significant relationships between LA dimensions and global or regional body fat depots.
\end{abstract}

Key words: Computed tomography angiography. Fatty depots. Left atrial dimensions. Obesity. Cardiovascular disease. Argentina.

\section{Resumen}

Antecedentes y objetivos: La relación entre los depósitos de grasa corporal y las dimensiones de la aurícula izquierda (Al) no ha sido del todo explorada. Nuestro objetivo es determinar si existe relación no solo con los depósitos de grasa corporal totales, sino específicamente con los depósitos grasos regionales. Materiales y métodos: Estudio observacional, retrospectivo, que incluyó pacientes consecutivos remitidos a nuestra institución con orden de realización de angiotomografía computarizada toracoabdominal gatillada con electrocardiograma por distintas indicaciones clínicas. Las mediciones de la Al se realizaron en la fase sistólica, utilizando vistas de cuatro y dos cámaras. Resultados: Se incluyeron un total de 87 pacientes.

\section{Correspondence:}

*Macarena C. De Zan

Av. Maipú, 1668

Date of reception: $28-02-2018$

Buenos Aires, Argentina

E-mail: maca_dezan@hotmail.com
Date of acceptance: 03-08-2018

DOI: 10.24875/ACME.M19000002
Available online: 09-08-2019 Arch Cardiol Mex (Eng). 2019;89(1):8-14 www.archivoscardiologia.com BY-NC-ND license (http://creativecommons.org/licenses/by-nc-nd/4.0/). 
La edad media fue de $66.4 \pm 12.5$ años; un $67 \%$ de los sujetos fueron hombres. El volumen de la Al indexado por la superficie corporal fue de $48.0 \pm 16.6 \mathrm{~cm}^{3} / \mathrm{m}^{2}$. Identificamos correlaciones significativas entre las dimensiones de la Al y la edad $(p<0.05)$. Sin embargo, no se evidenciaron correlaciones significativas entre las dimensiones de la Al y los distintos depósitos de grasa corporal, ya sea totales o regionales. Conclusiones: En este estudio, no identificamos relaciones significativas entre las dimensiones de la Al y los depósitos de grasa corporal globales o regionales.

Palabras clave: Angiotomografía computada. Depósitos grasos. Dimensiones de la aurícula izquierda. Obesidad. Enfermedad cardiovascular. Argentina.

\section{Introduction}

There is a relationship between obesity and increased risk of cardiovascular diseases and cardiometabolic alterations ${ }^{1,2}$. Various pathophysiological mechanisms have been postulated about cardiac structure and function adaptation and alteration in relation to body fat deposits, even in normotensive patients with no other apparent disease ${ }^{1-5}$. However, there is conflicting information in this regard. Horwich et al. referred to the "obesity paradox" when reporting a relationship between increased body mass index (BMI) and better prognosis in patients with heart failure $^{3,6,7}$. BMI and waist circumference have been used for years as body fat volume markers. Several studies have failed to unequivocally demonstrate a relationship between these markers and changes in cardiac structure ${ }^{8-15}$. This is assumed to be due to the fact that the causes of these alterations are regional deposits (mostly visceral and pericardial), rather than total body fat volume ${ }^{16,17}$.

For years, left atrial (LA) enlargement has been accepted as an indicator of both volume and pressure overload. In addition, recent studies have shown, through different diagnostic methodologies, that there is a relationship between the extent of epicardial fat surrounding the LA and atrial fibrillation ${ }^{18,19}$. However, in daily clinical practice it is not uncommon finding patients with normal atrial dimensions in the presence of systolic function deterioration and/or left ventricle enlargement ${ }^{20}$.

Currently, global and regional fat deposits measurement, as well as atrial dimensions estimation, can be performed in a single session with thoracoabdominal computed tomography angiography (CTA) with electrocardiogram (ECG) triggering. However, to the best of our knowledge, no study has comprehensively explored these relationships in a single session.

Therefore, the purpose of our work was to assess the relationship between regional and global body fat deposits and LA dimensions.

\section{Methods}

\section{Study population}

Observational study, which included consecutive patients referred to our institution between January 2016 and September 2017 for the performance of thoracoabdominal CTA for different clinical indications, including aortic dilatation, transcatheter aortic valve replacement guide, atherosclerotic disease or suspected acute aortic syndrome, among others. Among the patients with repeated acquisitions within the enrollment period, only the first examination was included. Patients with a history of endovascular treatment with aortic stent, aortobifemoral bypass surgery, valvular surgery, coronary artery bypass grafting or with confirmed acute aortic syndrome were excluded. A physician radiologist with experience in cardiovascular studies, blinded to the CTA images, collected data on demographic characteristics and cardiovascular risk factors. The presence of diabetes mellitus, hypercholesterolemia and hypertension was defined by history thereof documented in the clinical record and/or specific treatment for any of these conditions. The main purpose of the study was to assess the relationship between LA dimensions and different global and regional body fat deposits.

All tests were conducted in accordance with the ethical standards established in the Declaration of Helsinki of 1964 and its subsequent amendments. All the patients signed the habeas data.

\section{Image acquisition}

The images were acquired in three different locations using 64 and 128-row detector scanners (Brilliance ICT, Philips Healthcare, Cleveland, USA) and a 64-row detector, high-definition scanner (Discovery HD 750, GE Healthcare, Milwaukee, USA). An acquisition was made at inspiratory apnea that ranged from the supra-aortic trunks to the pubic symphysis. 


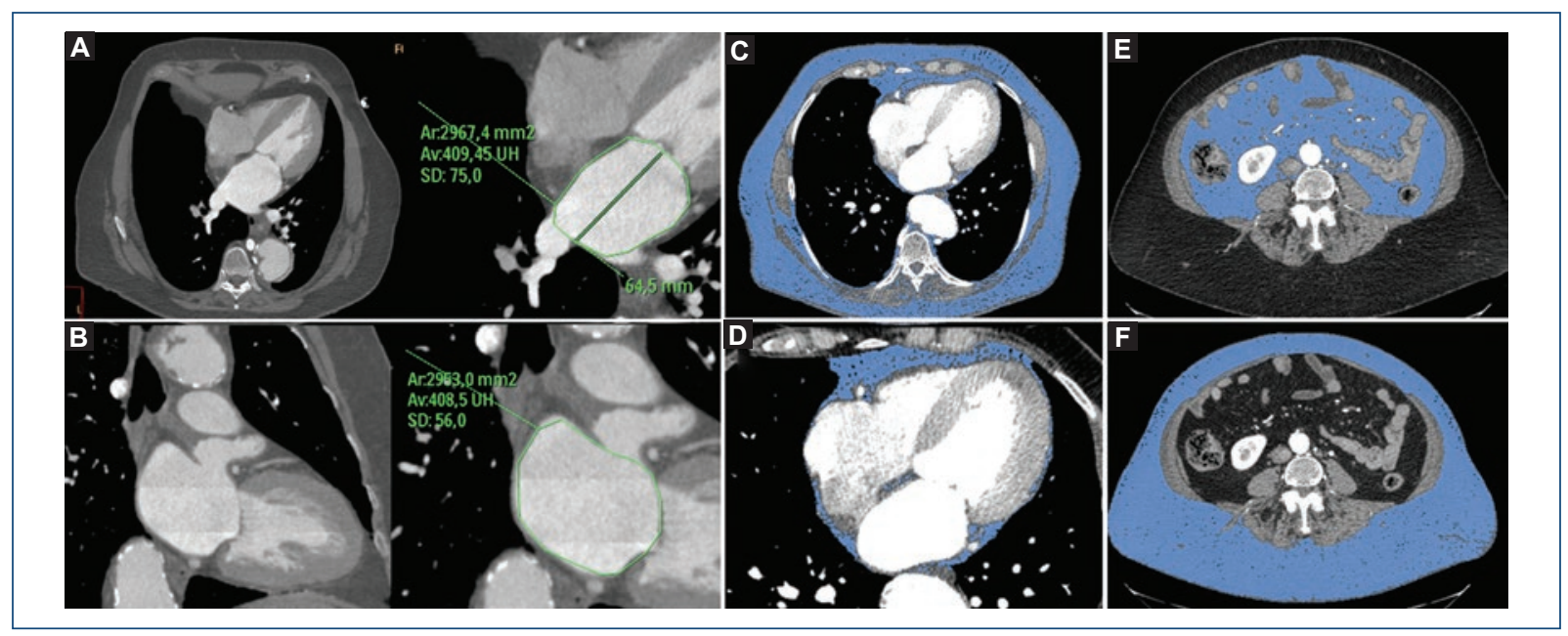

Figure 1. 70-year-old woman with hypertension and smoking as coronary risk factors, and BMI of $33 \mathrm{~kg} / \mathrm{m}^{2}$. Evaluation of left atrium dimensions in four-chamber $(\mathbf{A})$ and two-chamber $(\mathbf{B})$ views with multiplanar reconstructions obtained in $40 \%$ phase of the cardiac cycle. In the axial views (C, E and F) determinations of total (C), visceral (D) and subcutaneous body fat (E) are observed, with only tissue with a density between -190 and -30 Hounsfield units being enhanced. Panel D shows a four-chamber view with pericardial fat volume. Total body fat: $10,682 \mathrm{~cm}^{3} / \mathrm{m}^{2}$; thoracic fat: $3,047 \mathrm{~cm}^{3} / \mathrm{m}^{2}$; pericardial fat: $104 \mathrm{~cm}^{3} / \mathrm{m}^{2}(3.4 \%)$; abdominal fat: $7,634 \mathrm{~cm}^{3} / \mathrm{m}^{2}$; visceral fat: $2,148 \mathrm{~cm}^{3} / \mathrm{m}^{2}(28 \%$ of abdominal fat); subcutaneous fat: $5,486 \mathrm{~cm}^{3} / \mathrm{m}^{2}(72 \%$ of abdominal fat); subcutaneous fat thickness: $110.4 \mathrm{~mm}$; waist circumference: $118.6 \mathrm{~cm}$.

In our institution, thoracic aorta CTAs are acquired with ECG-triggering in order to avoid artifacts due to cardiac movement ${ }^{21}$. Among the patients with images acquired with the high-definition CT-scanner, only the thoracic aorta CTA was triggered with ECG, whereas abdominal CTA angiography was acquired immediately afterwards without triggering.

Acquisition parameters were: 100-120 kV (according to $\mathrm{BMI}), 150-400 \mathrm{~mA}$ (z-axis modulation was used), variable pitch, $0.5-0.75$ rotation time, DFOV adjusted to patient size, 1-2.5-mm section-thickness reconstructions and $0.5-2.5-\mathrm{mm}$ interval. Special care was taken to acquire images with a sufficiently wide field of vision in order to avoid missing data (subcutaneous fat).

Between 80-100 ml iodinated contrast medium (iobitridol, Xenetix $350^{\mathrm{TM}}$, Guerbet, France) were administered according to patient weight and to the CT-scanner used, based on a biphasic protocol, which consisted of a $100 \%$ contrast bolus injected at a rate of $4-4.5 \mathrm{ml} / \mathrm{s}$, followed by a $30-\mathrm{ml}$ bolus of physiological solution at $3-4 \mathrm{ml} / \mathrm{s}$.

\section{Image analysis}

The images were transferred to a workstation (Brilliance Workspace, Philips Healthcare, Cleveland, Ohio,
USA) and the analyses were performed by an observer blinded to clinical data.

Two phases of the cardiac cycle were saved for analysis, a systolic phase $(37.5-40 \%$ of the R-R interval) and a mesodiastolic one (75-78\% of the R-R interval). The systolic images were used for the assessment of atrial dimensions. Axial planes and multiplanar reconstructions (1-5 mm thick) were used to assess LA dimensions and body fat deposits.

To assess atrial dimensions, measurements were made in the two- and four-chamber views, obtained by adjusting the multiplanar reconstructions. LA maximum area (systolic) in both views and anteroposterior length in the four-chamber view were determined by manual planimetry (Fig. 1). This way, atrial volume was calculated using the biplanar area/length technique based on the following formula (0.85 x 4c Area $\times 2 c$ Area/ Perpendicular axis length from the mitral annulus to $L A$ posterior wall). Both the pulmonary veins left appendage and ostia were excluded from the analysis ${ }^{22,23}$. The measurements were subsequently indexed to the body surface area (Dubois \& Dubois).

BMI was defined as the weight in kilograms divided by the square of height in meters, and obesity was defined as BMI $\geq 30 \mathrm{~kg} / \mathrm{m}^{2}$. Fat tissue was calculated using a semiautomated volumetric module dedicated 
software (Brilliance Workspace, Philips Healthcare, Cleveland, Ohio, USA); fatty tissue was defined as tissue between -190 and -30 Hounsfield units ${ }^{24}$.

Total body fat volume was assessed from the thoracic operculum to the cranial region of the femoral heads using a volume reproduction technique and all measurements were indexed to the body surface area $\left(\mathrm{cm}^{3} / \mathrm{m}^{2}\right)$. For the fat volume measurements, the accuracy of all automatically detected tissues was verified and adjustments were manually and sequentially made in sagittal, coronal and axial views and using the three-dimensional fat coating (Fig. 1). Visceral fat volume was defined as the fat included in the visceral cavity, while abdominal subcutaneous fat volume was defined as abdominal fat volume minus visceral fat (Fig. 1). Pericardial fat volume was measured from $15 \mathrm{~mm}$ above the cranial margin of the left coronary trunk to the diaphragm. The thoracic wall delimited the anterior border, and the aorta and bronchi delimited the posterior border (posterior mediastinum was excluded). Epicardial and paracardial fat was included, in order to avoid pericardial discrimination errors, especially in thin patients. Following this line, the MESA study showed a very high correlation between pericardial and epicardial fat $^{25}$.

Finally, subcutaneous adipose tissue thickness (sum of anterior thickness and posterolateral thickness) was measured at the same level as the waist circumference measurement (iliac crests cranial end).

\section{Statistical analysis}

Discrete variables are presented as counts and percentages. Continuous variables are presented as means \pm standard deviations. Between-group comparisons were carried out using Student's t-test for independent samples, one-way analysis of variance and minimum least square difference (LSD) tests (post hoc comparisons), as indicated. The correlations between continuous variables were assessed using Pearson's correlation coefficients. Statistical analysis was performed using the SPSS ${ }^{\circledR}$ software, version 22 (Chicago, Illinois, USA). A p-value lower than 0.05 indicated statistical significance.

\section{Results}

Ninety patients were enrolled between January 2016 and September 2017. Three of them were excluded because they did not have the systolic phase available for LA evaluation. Therefore, a total of 87 patients
Table 1. Demographic characteristics. Indications for ECG-triggered CTA

\begin{tabular}{|l|c|}
\hline Age & $\mathbf{n = 8 7}$ \\
\hline Male gender & $66.4 \pm 12.5$ \\
\hline Hypertension & $58(67 \%)$ \\
\hline Hypercholesterolemia & $60(69 \%)$ \\
\hline Smoking & $29(33 \%)$ \\
\hline Diabetes mellitus & $44(51 \%)$ \\
\hline Indication & $14(16 \%)$ \\
\hline $\begin{array}{l}\text { Aortic enlargement } \\
\text { Ather to TAVI }\end{array}$ & \\
\hline $\begin{array}{l}\text { Aortic dissection } \\
\text { Other }\end{array}$ & $51(59 \%)$ \\
\hline \begin{tabular}{l} 
Aortic aneurysm \\
\hline
\end{tabular} & $18(21 \%)$ \\
\hline
\end{tabular}

AAA: abdominal aortic aneurysm; CTA; computed tomography angiography; TAVI: transcatheter aortic valve percutaneous implantation.

constituted the study population. Mean age was $66.4 \pm 12.5$ years. Fifty-eight patients $(67 \%)$ were males, with a mean BMl of $29.1 \pm 5.6 \mathrm{~kg} / \mathrm{m}^{2}$ (Table 1). In $36 \%$ of patients, CTA confirmed the presence of aortic aneurysm. Among the indications, more than half the studies were requested due to aortic enlargement; $21 \%$ prior to aortic valve percutaneous implantation, $10 \%$ for atherosclerotic disease or for suspected abdominal aortic aneurysm, $5 \%$ as follow-up of aortic dissection and $6 \%$ for other causes (Table 1).

\section{Relationships between atrial dimensions and global and regional body fat deposits}

The LA dimensions were assessed using different parameters, with a mean area of $24.9 \pm 7.2 \mathrm{~cm}^{2}$ in the four-chamber view and $25.2 \pm 6.2 \mathrm{~cm}^{2}$ in the two-chamber view. Mean indexed volume was $48.0 \pm 16.6 \mathrm{~cm}^{3} / \mathrm{m}^{2}$. There were no significant differences between genders with regard to LA dimensions (males, $47.4 \pm 16.6 \mathrm{~cm}^{3} / \mathrm{m}^{2 v s}$. females, $\left.49.4 \pm 16.4 \mathrm{~cm}^{3} / \mathrm{m}^{2} ; \mathrm{p}=0.61\right)$.

As for the correlations of LA dimensions with different demographic and morphological variables, significant (although weak) relationships were only recorded with age (with the area indexed in four chambers $[r=0.37$, $p<0.0001]$ and in two chambers $[r=0.37, p<0.0001])$ and with indexed volume $(r=0.33, p=0.002)$. Patients with hypertension had a higher indexed $L A$ volume than those without hypertension $(51.3 \pm 17.3$ vs. $40.8 \pm 12.4$ $\mathrm{cm}^{3} / \mathrm{m}^{2} ; \mathrm{p}=0.006$ ). 
Table 2. Quantification of general and regional body fat deposits discriminated in left atrial volume $\left(\mathrm{cm}^{3} / \mathrm{m}^{2}\right)$ groups (tertiles).

\begin{tabular}{|c|c|c|c|c|c|}
\hline & \multicolumn{3}{|c|}{ Left atrial volume } & \multirow[t]{3}{*}{$\mathbf{p}$} & \multirow[t]{3}{*}{ T1 vs. T3 } \\
\hline & Lower tertile & Middle tertile & Upper tertile & & \\
\hline & $n=29$ & $n=29$ & $n=29$ & & \\
\hline Body mass index $\left(\mathrm{kg} / \mathrm{m}^{2}\right)$ & $30.7 \pm 6.6$ & $27.7 \pm 4.9$ & $28.8 \pm 4.9$ & 0.12 & 0.20 \\
\hline Waist circumference & $103.2 \pm 10.4$ & $100.0 \pm 12.3$ & $103.3 \pm 11.1$ & 0.46 & 0.98 \\
\hline Total fat $\left(\mathrm{cm}^{3} / \mathrm{m}^{2}\right)$ & $8,569.6 \pm 2,576.0$ & $7,534.3 \pm 2,874.2$ & $8,209.3 \pm 2,705.7$ & 0.34 & 0.61 \\
\hline Abdominal fat $\left(\mathrm{cm}^{3} / \mathrm{m}^{2}\right)$ & $6,160.7 \pm 1,744.1$ & $5,376.2 \pm 2,180.5$ & $5,758.7 \pm 1,933.4$ & 0.32 & 0.44 \\
\hline Pericardial fat $\left(\mathrm{cm}^{3} / \mathrm{m}^{2}\right)$ & $109.0 \pm 50.3$ & $91.7 \pm 41.6$ & $118.4 \pm 73.4$ & 0.20 & 0.53 \\
\hline Visceral fat $\left(\mathrm{cm}^{3} / \mathrm{m}^{2}\right)$ & $2,845.4 \pm 906.2$ & $2,178.3 \pm 1,250.0$ & $2,499.9 \pm 1,342.9$ & 0.11 & 0.26 \\
\hline Subcutaneous fat $\left(\mathrm{cm}^{3} / \mathrm{m}^{2}\right)$ & $3,318.3 \pm 1,386.1$ & $3,199.5 \pm 1,276.8$ & $3,258.8 \pm 1,174.4$ & 0.94 & 0.86 \\
\hline Subcutaneous fat thickness (mm) & $90.4 \pm 27.6$ & $89.1 \pm 29.0$ & $81.2 \pm 19.1$ & 0.33 & 0.17 \\
\hline
\end{tabular}

${ }^{*}$ Minimal difference post hoc tests.

No significant correlations were identified between indexed atrial volume and global fat deposit markers (BMI: $r=-0.11, p=0.32$; and total body fat volume: $r=-0.08, p=0.48$, respectively) or visceral fat volume $(r=-0.13, p=0.24)$.

Very weak correlations were identified between atrial volume and both pericardial fat volume and waist circumference $(r=0.23, p=0.035$ and $r=0.24, p=0.03$, respectively), although they lost statistical significance after indexation by body surface area $(r=0.05, p=0.65$ and $r=-0.03, p=0.78$, respectively).

When LA dimensions were discriminated in three equal groups (tertiles), a significant incremental relationship with age was identified $(p=0.001$ ). No significant relationships were identified between these groups (LA volume tertiles) and global or regional body fat parameters both in total population (Table 2) and in the analysis discriminating according to the presence of hypertension (Supplementary Material Table).

\section{Discussion}

With the passage of years, ventricular distensibility gradually decreases, consequently leading to an increase in atrial filling pressures and dimensions. In our work, this is reflected (offering to a certain extent a parameter for atrial measurements internal validation) on the identification of a significant, albeit weak, relationship between age and LA dimensions.

In this context, we found no association between different general or regional obesity markers (including pericardial and visceral fat) and LA dimensions.
Although this could be partly attributed to an elevated prevalence of risk factors with potential influence on atrial dimensions, it could also be postulated that hemodynamic changes do not always translate into changes in LA morphology. In fact, as previously mentioned, it is not uncommon finding patients with normal atrial dimensions in the presence of systolic function deterioration and/or left ventricle enlargement in everyday clinical practice ${ }^{20}$. In the same lines, a magnetic resonance imaging study showed a significant relationship between visceral fat and LA ejection fraction deterioration, with preserved atrial volumes ${ }^{26}$.

The obesity paradox is another clear example. Obesity is an epidemic with great impact on morbidity and mortality at the global level. However, the obesity paradox, i.e., the inconsistent and sometimes divergent relationship between obesity and prognosis, places the physician before a dilemma, particularly when using BMI as an adiposity marker ${ }^{16,27-29}$.

Different studies have shown that obesity is associated with an increase in patient cardiovascular risk. In fact, two possible mechanisms are postulated, an indirect one and a direct one, by means of which fatty deposits would exert their toxic action ${ }^{5}$. With regard to the indirect mechanism, obesity generates an increase in basal metabolism, an increase in total body blood volume and volume/minute, and a decrease in peripheral vascular resistance ${ }^{1}$. Within the pathophysiological mechanisms postulated for morphological and functional cardiovascular changes, it is admitted that, owing to the Frank-Starling mechanism, volume overload would lead to ventricular dilation, with a consequent increase 
in parietal stress followed by eccentric hypertrophy and LA enlargement ${ }^{1,30-33}$.

Regarding the direct mechanisms, although it is controversial, it is suggested that pericardial fat might mechanically compress the atria and ventricles, which would decrease ventricular compliance, thus affecting left ventricle diastolic properties ${ }^{3,30,34-36}$. This would determine ventricular hypertrophy, with atrial dilation and disrupted ventricular filling. On the other hand, the role of adipose tissue as an active metabolic organ, capable of secreting different pro-inflammatory cytokines associated with increased cardiovascular risk, is well established ${ }^{5}$. It should be highlighted that this activity is mainly attributed to visceral and pericardial fat, which would partially explain the "obesity paradox", with a lack of correlation between cardiovascular conditions and classic obesity markers (weight, BMl, waist circumference, etc. $)^{12,17,27-29,37}$.

Focusing now on LA morphological changes and global and regional fat deposits, different studies have tried to demonstrate associations.

Numerous clinical trials have reported a significant relationship between the epicardial fat that surrounds the LA and the development of atrial fibrillation, although its relationship with atrial dimensions is inconclusive $^{19,38}$. It should be noted that, in general, these works specifically evaluated epicardial fat surrounding the LA, whereas in our investigation we assessed pericardial fat volume including both epicardial and paracardial fat from $15 \mathrm{~mm}$ above the left coronary trunk to the diaphragm. Although this strategy improves the reproducibility of measurements and there is a high correlation between pericardial and epicardial fat, a recent study demonstrated significant immunohistochemical differences between epicardial and paracardial adipose tissue ${ }^{38}$. This might explain, at least partially, the different findings observed in our study.

Poirier et al. reported a significant association between pericardial fat and LA diameter, although this was observed only in women, and with a lower correlation than those observed with BMI and waist circumference ${ }^{1}$. Furthermore, lacobellis et al. demonstrated a significant association between increased epicardial fat and both atrial dilation and ventricular relaxation alterations in patients with morbid obesity 4 .

As previously mentioned, in the present study we did not find a significant relationship between classic obesity markers and LA dimensions, as well as neither with pericardial and/or visceral fat deposits. One of the possible reasons of the lack of correlation could be associated with the fact that atrial dimensions are not always a sensitive overload indicator. In fact, different parameters are currently being jointly evaluated in the assessment of atrial involvement (atrial dimensions, longitudinal strain, fibrosis and left atrial appendage peak velocity, among others $)^{39}$. Alternatively, visceral and/or pericardial fat deposits might in effect not be related to significant hemodynamic modifications. Further studies should be carried out to corroborate the different hypotheses.

Some limitations should be recognized, including the small sample size. The particularity of the present study is also associated with certain selection bias, resulting from assessing all global and regional fatty deposits in a single session (thoracoabdominal CTA). It should be noted that the population included in our study was relatively old in comparison with other studies, and had a high prevalence of coronary risk factors. These previous conditions might influence on atrial dimensions, due to the lack of a control group without risk factors or known cardiovascular disease for assessing in an unbiased manner the respective associations or a sufficient sample size to perform logistic regression analyses. Furthermore, no complete information was available about comorbidities that might affect atrial dimensions, including the presence of supraventricular arrhythmia and valvular heart disease, among others. In addition, given the anatomical characteristics derived from CT imaging, the readers were not blinded to patient body habitus. It should be noted that waist circumference measurements cannot be directly extrapolated to conventional anthropometric measurement, since the latter is performed at the end of expiration and with the subject standing.

\section{Conclusion}

In this study, which to our knowledge is the first one focused on assessing the relationship between global and regional fat deposits and LA dimensions in a single session, we failed to find a significant relationship between both. Future, larger studies, preferably including functional assessment techniques such as atrial strain, should explore whether our findings could be attributed (or not) to the fact that fat body deposits are not always related to expected hemodynamic changes.

\section{Funding}

The present investigation has not received specific support from agencies of the public sector, commercial sector or non-profit entities. 


\section{Conflicts of interest}

We declare that Patricia Carrascosa is a consultant for General Electric (GE). There are no conflicts of interest involving any of the other authors.

\section{Ethical disclosures}

Protection of people and animals. The authors declare that no experiments have been conducted on humans or animals for this research.

Confidentiality of data. The authors declare having followed the protocols of their work center on the publication of patient data.

Right to privacy and informed consent. The authors declare that no patient data appear in this article.

\section{References}

1. Poirier P, Giles TD, Bray GA, Hong Y, Stern JS, Pi-Sunyer FX et al. Obesity and cardiovascular disease: pathophysiology, evaluation, and effect of weight loss: an update of the 1997 American Heart Association Scientific Statement on Obesity and Heart Disease from the Obesity Committee of the Council on Nutrition, Physical Activity, and Metabolism. Circulation. 2006;113(6):898-918

2. Ortega FB, Lavie CJ, Blair SN. Obesity and cardiovascular disease. Circ Res. 2016;118(11):1752-70.

3. Liu J, Fox CS, Hickson DA, May WL, Ding J, Carr JJ, et al. Pericardial fat and echocardiographic measures of cardiac abnormalities: the Jackson Heart Study. Diab Care. 2011;34(2):341-6.

4. lacobellis G, Leonetti F, Singh N, M Sharma A. Relationship of epicardial adipose tissue with atrial dimensions and diastolic function in morbidly obese subjects. Int J Cardiol. 2007;115(2):272-3.

5. Marcano Y, Torcat J, Ayala L, Verdi B, Lairet C, Maldonado M, et al. Funciones endocrinas del tejido adiposo. Revisión. Rev Venezol Endocrinol Metabol. 2006;4(1).

6. Srikanthan P, Horwich TB. The obesity paradox: time for a new look at an old paradigm. Rev Esp Cardiol. 2012;65(5):403-4.

7. Horwich TB, Fonarow GC, Hamilton MA, MacLellan WR, Woo MA, Tillisch $\mathrm{JH}$. The relationship between obesity and mortality in patients with heart failure. J Am Coll Cardiol. 2001;38(3):789-95.

8. Mehta T, Fontaine KR, Keith SW, Bangalore SS, de los Campos G, Bartolucci $A$, et al. Obesity and mortality: are the risks declining? Evidence from multiple prospective studies in the United States. Obes Rev. 2014;15(8):619-29.

9. Niraj A, Pradhan J, Fakhry H, Veeranna V, Afonso L. Severity of coronary artery disease in obese patients undergoing coronary angiography: "obesity paradox" revisited. Clin Cardiol. 2007;30(8):391-6.

10. Wee CC, Huskey KW, Ngo LH, Fowler-Brown A, Leveille SG Mittlemen MA, et al. Obesity, race, and risk for death or functional decline among Medicare beneficiaries: a cohort study. Ann Int Med. 2011;154(10):645-55

11. Mukherjee $D$, Ojha $C$. Obesity paradox in contemporary cardiology practice. JACC Cardiovasc Interv. 2017;10(13):1293-4.

12. Bouchi R, Takeuchi T, Akihisa M, Ohara N, Nakano Y, Nishitani R, et al. High visceral fat with low subcutaneous fat accumulation as a determinant of atherosclerosis in patients with type 2 diabetes. Cardiovasc Diabetol. 2015;14:136

13. Shah RV, Anderson A, Ding J, Budoff M, Rider O, Petersen SE, et al. Pericardial, but not hepatic, fat by CT is associated with CV outcomes and structure: The Multi-Ethnic Study of Atherosclerosis. JACC Cardiovasc Imaging. 2017:10(9):1016-27.

14. Fernández M, Basurto L, Córdova N, Vázquez A, Tepach N, Degollado J. Epicardial adipose tissue is associated with visceral fat, metabolic syndrome, and insulin resistance in menopausal women. Rev Esp Cardio (Engl Ed). 2014;67(6):436-41.

15. Ladeiras-Lopes R, Sampaio F, Bettencourt N, Fontes-Carvalho R, Ferreira N, Gama V, et al. The ratio between visceral and subcutaneous abdominal fat assessed by computed tomography is an independent predictor of mortality and cardiac events. Rev Esp Cardiol (Engl Ed). 2017;70(5):331-7.

16. Rodriguez-Granillo GA, Carrascosa P. Abdominal obesity as risk predictor. Closer than body mass index but not close enough. J Am Coll Cardiol. 2018;71(12):1398-1399.

17. Rodriguez-Granillo GA, Reynoso E, Capunay C, Carpio J, Carrascosa P. Pericardial and visceral, but not total body fat, are related to global coronary and extra-coronary atherosclerotic plaque burden. Int J Cardiol. 2018;260:204-10.

18. Zhu W, Zhang H, Guo L, Hong K. Relationship between epicardial adipose tissue volume and atrial fibrillation: A systematic review and meta-analysis. Herz. 2016:41(5):421-7.

19. Nakamori S, Nezafat M, Ngo LH, Manning WJ, Nezafat R. Left atrial epicardial fat volume is associated with atrial fibrillation: a prospective cardiovascular magnetic resonance 3D Dixon study. J Am Heart Assoc. 2018;7(6)

20. Morris DA, Belyavskiy E, Aravind-Kumar R, Kropf M, Frydas A, Braunauer $\mathrm{K}$, et al. Potential usefulness and clinical relevance of adding left atrial strain to left atrial volume index in the detection of left ventricular diastolic dysfunction. JACC Cardiovasc Imaging. 2018:11(10):1405-15.

21. Carrascosa P, Capunay C, Deviggiano A, Rodriguez-Granillo GA, Sagarduy MI, Cortines $\mathrm{P}$, et al. Thoracic aorta cardiac-cycle related dynamic changes assessed with a 256-slice CT scanner. Cardiovasc Diagn Ther. 2013;3(3):125-8.

22. Takagi Y, Ehara S, Okuyama T, Shirai N, Yamashita H, Sugioka K, et al. Comparison of determinations of left atrial volume by the biplane area-length and Simpson's methods using 64-slice computed tomography. J Cardiol. 2009;53(2):257-64.

23. Whitlock M, Garg A, Gelow J, Jacobson T, Broberg C. Comparison of left and right atrial volume by echocardiography versus cardiac magnetic resonance imaging using the area-length method. Am J Cardiol. 2010; 106(9):1345-50.

24. Shah RV, Murthy VL, Abbasi SA, Blankstein R, Kwong RY, Goldfine AB, et al. Visceral adiposity and the risk of metabolic syndrome across body mass index: the MESA Study. JACC Cardiovasc Imaging. 2014;7(12):1221-35.

25. Ding J, Hsu FC, Harris TB, Liu Y, Kritchevsky SB, Szklo M, et al. The association of pericardial fat with incident coronary heart disease: The Multi-Ethnic Study of Atherosclerosis (MESA). Am J Clin Nutr. 2009;90(3):499-504.

26. Nyman K, Graner M, Pentikainen MO, Lundbom J, Hakkarainen A, Siren R, et al. Metabolic syndrome associates with left atrial dysfunction. Nutr Metab Cardiovasc Dis. 2018;28(7):727-34.

27. Sharma A, Vallakati A, Einstein AJ, Lavie CJ, Arbab-Zadeh A, Lopez-Jimenez $F$, et al. Relationship of body mass index with total mortality, cardiovascular mortality, and myocardial infarction after coronary revascularization: evidence from a meta-analysis. Mayo Clin Proc. 2014;89(8):1080-100.

28. Sharma A, Lavie CJ, Borer JS, Vallakati A, Goel S, Lopez-Jimenez F, et al. Meta-analysis of the relation of body mass index to all-cause and cardiovascular mortality and hospitalization in patients with chronic heart failure. Am J Cardiol. 2015;115(10):1428-34.

29. Uretsky S, Supariwala A, Singh P, Atluri P, Khokhar SS, Koppuravuri HK, et al. Impact of weight on long-term survival among patients without known coronary artery disease and a normal stress SPECT MPI. J Nucl Cardiol. 2010;17(3):390-7.

30. Alpert MA. Obesity cardiomyopathy: pathophysiology and evolution of the clinical syndrome. Am J Med Sci. 2001;321(4):225-36.

31. Kasper EK, Hruban RH, Baughman KL. Cardiomyopathy of obesity: a clinicopathologic evaluation of 43 obese patients with heart failure. Am J Cardiol. 1992;70(9):921-4.

32. Messerli FH. Cardiopathy of obesity--a not-so-Victorian disease. New Engl J Med. 1986;314(6):378-80

33. Ku CS, Lin SL, Wang DJ, Chang SK, Lee WJ. Left ventricular filling in young normotensive obese adults. Am J Cardiol. 1994;73(8):613-5.

34. Stojanovska J, Cronin P, Patel S, Gross BH, Oral H, Chughtai K, et al. Reference normal absolute and indexed values from ECG-gated MDCT: left atria volume, function, and diameter. AJR. Am J Roentgenol. 2011;197(3):631-7.

35. lacobellis G, Ribaudo MC, Zappaterreno A, lannucci CV, Leonetti F. Relation between epicardial adipose tissue and left ventricular mass. Am J Cardiol. 2004:94(8):1084-7.

36. Fox CS, Gona P, Hoffmann U, Porter SA, Salton CJ, Massaro JM, et al. Pericardial fat, intrathoracic fat, and measures of left ventricular structure and function: the Framingham Heart Study. Circulation. 2009;119(12):1586-91.

37. Rodriguez-Granillo GA Carrascosa $P$ Deviggiano A Capunay $C$ De Zan MC, Goldsmit A, et al. Pericardial fat volume is related to atherosclerotic plaque burden rather than to lesion severity. Eur Heart $J$ Cardiovasc Imaging. 2017:18(7):795-801.

38. He Y, Ma N, Tang M, Jiang ZL, Liu H, Mei J. The differentiation of beige adipocyte in pericardial and epicardial adipose tissues induces atrial fibrillation development. Eur Rev Med Pharmacol Sci. 2017;21(19):4398-405

39. Delgado V, Di Biase L, Leung M, Romero J, Tops LF, Casadei B, et al. Structure and function of the left atrium and left atrial appendage: AF and stroke implications. J Am Coll Cardiol. 2017;70(25):3157-72. 